\title{
Macrothink

\section{The Effectiveness of the Logic of English Approach on the Improvement of Reading Skills of Saudi EFL Learners}

\author{
Mohammed Hassan Abdel Rahman Ibrahim \\ English Department Lecturer, Al Ula Branch \\ Taibah University, Saudi Arabia \\ E-mail: mohd7797@gmail.com
}

Received: November 30, 2015 Accepted: January 17, 2016 Published: January 18, 2016

doi:10.5296/elr.v2i1.8640 URL: http://dx.doi.org/10.5296/elr.v2i1.8640

\begin{abstract}
The purpose of this study is to examine the extent to which the use of the Logic of English Approach can improve reading skills of Saudi EFL learners at the college of Preparatory Year Program (PYP), Ula Branch, in Taibah University. The Logic of English Approach attempts to integrate teaching with reading skills such as, reading comprehension, reading fluency, vocabulary, literacy and writing skills. The present study attempts to check only the effectiveness of this approach on the enhancement of reading fluency and comprehension. The Logic of English Approach assumes that the improvement of reading fluency depends on intensive teaching and practice of spelling rules using phonics, phonograms, and word roots Eide (2012). To achieve the aim of this study, quantitative research methodology was conducted. The data were collected from lecturers of Taibah University, arranged in tables, interpreted and compared with past studies. The results match most of the previous research.
\end{abstract}

Keywords: Logic of English, Phonograms, Word roots, Phonics.

\section{Introduction}

During six years of experience in teaching EFL four skills to first year university students, at Preparatory Year Program (PYP), in Kingdom of Saudi Arabia, teachers observed that it was hard for the majority of students to recognize and pronounce words correctly. Although English is taught as basic subject and it is a means of instruction student can take a deep breath to say a single word with low speed and wrong pronunciation. I also discovered that most students experience difficulties in EFL word spelling. These difficulties in English spelling affect students' reading accuracy and reading comprehension. 


\section{Macrothink}

The course taught at PYP is called Q Skills Course. It focuses on developing the skills of English language using two books for that, one book for reading and writing and another one for listening and speaking. The course was designed on the grounds that students have already studied elements of English literacy at schools before coming to university. The educational goals of English language in public schools include student's writing a letter or an email to his/her friend. Write about your daily routine. Describe buildings and places as well as talk about yourself or a weather. At the college of PYP, learners are asked to write essays about sports or cultures, describe buildings and places using present simple. They talk about past events or tell stories as well as English is the language of teaching. But unfortunately, students came to university with very limited knowledge of English language. This limitation of knowledge hinders students from dealing with Q Skills Course, therefore, some students get depressed, frustrated, and some, may even leave university.

As a result, the Dean of Preparatory Year Programmme (PYP) asked teachers to prepare remedial lessons to develop students' level in reading skills. What is required more is to arrange learning materials that lead students to acquire reading fluency and comprehension. But the most crucial problem for the students as well as the teachers is the nature of English Language itself. This nature of language is the major trouble for students to read. For example, there is no one to one correlation between English alphabet and their sounds that they represent. If we look at English spelling, it is easy to understand why there is a need for a phonetic alphabet. In this concern, Fromkin, Rodman, and Hyams (2007) have mentioned that different letters may represent a single sound, as shown in the following instances:

through threw to too two

A single letter may represent different sounds:

Tape sad father ball many collage

A combination of letters may represent a single sound:

shop physics special meal cough station train

Some letters have no sound at all in certain words:

Answer castle psychopath debt comb wrong fasten know

So, no doubt, we need a complete English method or Approach to give evidenced sources of information to this problem and helps students to develop their reading skills. The appropriate English Approach that solves this vital problem is our issue in this study.

\section{Statement of the Problem}

The inconsistency of English Spelling leads to difficulties in students' oral reading fluency. Many students for instance, do not pronounce some words correctly because many English words are not spelled as they are spoken. English language has 26 letters which represent 45 sounds. These 45 sounds on the other hand are represented by 75 basic phonograms. Among these phonograms, there are 23 phonograms which have more than one sound. In addition, there are 30 spelling rules that interact with these phonograms Eide (2012). 
Continuing with Dr. Eide's views, Johnson (2013) stated that the most important factor in reading fluency and reading comprehension lies in students' ability to spell words accurately. Students' spelling abilities play an essential role in their reading fluency, as well as, reading comprehension. Bayetto et al. (2013) also revealed that Phonics instruction is a major component of a comprehensive literacy program because it is a high-yield strategy to draw upon when attempting to say unknown words. All students need to be taught how to develop increasingly independent decoding skills.

Another major problem identified in this research is the lack of phonemic awareness which leads to the worsening of student's reading fluency. Phonemic awareness is a clear understanding of words that comprised of individual sounds glued together. If students do not practice gluing words together such as, compound words, one-syllable words or two or more syllable words, they do not master reading fluency as well as the pronunciation of some simple words. In this point, Eide (2012) mentioned that Students who lack phonemic awareness often appear to be guessing while reading. This is the reason why the National Reading Panel (NRP) stated that teaching phonemic awareness to children significantly improves their reading development.

Moreover, the lack of word formation awareness also leads to difficulties in student's reading fluency as well as reading comprehension. Knowing the idea of adding prefixes to the word root to change the meaning of words and adding suffixes to the word stem to change the class of words is an important factor in increasing students' oral reading fluency and comprehension. One observation has been made with native speakers of English is that the better they are at being aware of the smallest units of meaning in words (i.e., prefixes, suffixes and roots), the better they are at understanding text and gaining vocabulary (Tyler \& Nag, 1990).

In the same way, Tahaineh (2012) claimed that recognizing how new words are formed, may not be always very easy in a language such as English. Since these words are formed, a lot of changes might appear during or after the new formation, concerning parts of speech, spelling, meaning, stress and sound which make their identification more difficult to the EFL learners.

\section{Significance of the Study}

This study attempts to contribute to the followings:

1). Testing the Logic of English Approach as a unique method of English language teaching contributes to the area of Applied Linguistics.

2). Going back to the roots of English words, study them systematically with sufficient examples from various European languages, gives a good support to researchers of etymology, philology and translation studies.

3). The additional resources of phonograms for developing learners phonemic awareness provide a good insight for teachers and teacher trainers to plan properly lessons and methods of teaching.

4). This study brings the Logic of English Approach as one of the best English teaching 


\section{Macrothink}

methods which facilitates so many English language problems to teachers and learners of English as foreign language.

5). This research encourages teachers and teacher trainers to use and develop materials for teaching phonics and phonograms.

6). Introducing 30 spelling rules with sufficient examples and tasks of vowels, consonants and syllables is a great contribution to English language readers and writers. This also helps university students to develop their oral reading fluency.

7). The deeply word roots study with clear justifications of many English structures narrows the idea of "English is an exceptional language".

8). In this study, the integration of phonograms, spelling rules and word roots studies is considered as a good discipline to teachers and teacher trainers to plan correctly how to teach English language skills.

\section{Research Objectives}

The objectives of this research are stated in the following points:

1). To examine the efficiency of the Logic of English Approach on the development of reading fluency and comprehension of Saudi EFL Learners.

2). To examine the use of phonics and phonograms on the improvement of students' reading fluency and comprehension.

3). To explore the use of word roots on the enhancement of students' reading comprehension

4). To explore the Logic of English Approach as appropriate method for teaching reading fluency and reading comprehension.

\section{Research Questions}

Based on the objectives of the present study, the research questions are as follows:

1). Does the effective use of the Logic of English Approach develop reading fluency and comprehension of Saudi EFL Learners?

2). Does the use of phonics and phonograms improve students' reading fluency and comprehension?

3). Does the use of word roots enhance students' reading comprehension?

4). Does the Logic of English Approach act as appropriate method of teaching reading fluency and reading comprehension?

\section{Research Methodology}

The present study was prepared following quantitative research methodology. The quantitative study has been selected because it brings numerical data from sample population using questionnaire. It also analyses and evaluates participants' points of views using 
statistical tables. The results of the study were compared with previous studies and considered to be a foot step towards future studies (Creswell, 2014).

\subsection{Participants}

The participants of this study were English instructors from Deanship of Preparatory Year Program and English lecturers from College of Arts and Sciences at Ula Branch, in Taibah University. In order to get good insights and clear visions of the problem we selected 28 teachers, 18 male and 10female. These teachers suffer a lot from the deterioration of their students' levels of reading comprehension.

\subsection{Instruments}

In order to collect information from English lecturers, the researcher prepared a questionnaire and gave it to them. The activities of this questionnaire were taken from A systematic Approach to Reading, Spelling, and Writing Book by Dr. Denis Eide. The activities were intended to facilitate difficulties in English spelling and to enhance oral reading fluency for first year university students at PYP, Ula Branch, in Taibah University. These activities of present study include foundations for reading: Phonemic awareness, phonograms, spelling rules and English word roots.

The purpose of this questionnaire is to help educators access, to some degree, the effectiveness of the logic of English approach in reading development. Although measuring the logic of English approach effectiveness is not an easy task, I have found that teachers responses are a helpful source of information on the suitability of the logic of English approach in reading fluency development.

\section{Literature Review}

The Logic of English Approach focuses on the following points:

\subsection{Foundation for Reading: Phonemic Awareness and Phonograms}

According to the Logic of English Approach, foundations for reading skills involve leading learners to the next stage through oral language development. Following written language development stages improves learners reading skills. Phonemic awareness is basic foundation of reading development. Learning by phonograms helps learners develop reading skills.

It is well known that oral language development has some stages such as pre linguistic stage, one word stage, early and later combinatory speech. On the other hand, written language also has some steps such as controlled scribbling, letter like forms and letter and symbols relationship. This study assumes that the best way for the child to learn is to cope with these stages. Along with this point, Hammill (2004) declared that children's understanding of names and sounds of English letters earlier is the best predictor of their later reading abilities. There is also strong research support the efficacy of explicitly teaching alphabet letters because it is deemed to be one of the best indications of later reading achievement (Baroody \& Diamond, 2012; Hogan, Catts, \& Little, 2005).

Phonemic awareness, as defined in the Logic of English Approach is a clear understanding of 
words which involve individual sounds pronounced together. A learner who does not have basic information of phonemic awareness suffers a lot in reading passages. After examining a wide body of research, the National Reading Panel concluded that students who receive systematic and explicit phonics instruction are more likely to experience reading success than students receiving non-systematic phonics instruction or no phonics instruction at all. That is, phonics instruction promotes reading success and is more effective when a set of letter-sound relationships is taught directly and in a clearly defined, logical sequence. As an essential part of that process, children must be given enough opportunities to apply what they are learning about letters and sounds to the reading of words, sentences, and even books.

For the above reason, In 2000, the National Reading Panel (NRP) of the National Institute of Child Health and Development (NICHD) issued a report that identified five areas that were critical for effective reading instruction: phonemic awareness, phonics, fluency, vocabulary, and comprehension.

Similarly, phonograms are the most basic building blocks of all words in a phonetic language. Many adults in the U.S. know how to spell tens of thousands of words, but they don't have any idea why they are spelled in such manner, specially long words (Eide, 2012). Some research studies indicate that students who learn phonics do better in aspects of reading word identification, accuracy of oral reading, and silent reading, comprehension and fluencythan those who do not learn it. This point was clearly supported by Fambro (2011) who mentioned that English language has twenty six letters in its alphabet and those letters have forty five sounds, or phonemes, either alone or blended together. If a child can recognize the letters but not the phonemic sounds it has, then they usually have a difficult time with reading comprehension, fluency and spelling.

\subsection{Learning Styles and Differences}

The way individual learner prefers to learn something is a very important for developing reading skills. All students learn faster and deeper with multi modality teaching. In reading and physical development, many children's eyes struggle to consistently track left to right. Also learners must be trained for a good physical reading development.

According to the Logic of English Approach, at the beginning of every academic year, there must be a diagnosis of students' Learning style. There are three main types of learners:

Auditory learner: - A learner who remembers things more easily when they hear them spoken. This sort of learners may like the teacher to say a new word aloud and not just to write it on the board. Kinesthetic learner: - A learner who learns more easily by doing things physically. This kind of learner may like to move around in classroom or remove objects while learning. Visual learner:- A learner who finds it easier to learn when they can see things written down or in pictures. This learner may like the teacher to write a new word on the board and not just to say it aloud.

Previous studies have reported that students' learning performance could be improved if proper learning style dimensions could be taken into consideration when developing adaptive learning system (Filippidis \& Tsoukalas, 2009; Graf, Liu, \& Kinshuk, 2010; Hauptman \& 
Cohen, 2011).

In the same way, multimodal teaching is a style in which students learn material through a number of different sensory modalities. For example, a teacher may create a lesson in which students learn through auditory and visual methods, or visual and demonstrative methods. This successful teaching style implements many strategies to ensure students understand and retain information. This interactive teaching way breaks monotony and reinforces overall EFL learning.

As per the Logic of English Approach, reading skills maintain a component of visual muscle memory. The eyes are muscles that must be learned to move in the direction of reading and writing. Many learners' eyes struggle to move from one side to other, therefore, they must be trained for a good physical reading development. Scientifically-based research suggests that ELLs respond well to meaningful activities such as language games and word walls, especially when the activities are consistent and focus on particular sounds and letters. Songs and poems, with their rhythm and repetition, are easily memorized. Hieber et al. (2002).

\subsection{Suggested Solutions}

The suggested solutions include studying multiple spellings of sounds facilitates learner's reading. There must be an intensive teaching and practice of spelling rules. There must also be an intensive teaching and practice of phonics, phonograms and word roots.

In terms of spelling sounds, the Logic of English Approach prepares many charts including sound to spelling reference, only 15 of 45 sounds are represented by only one spelling reference, 22 sounds have rare spellings as well as a chart for common sounds with multiple spelling references. As it shown in the table below.

Table 1. It represents the common spelling references for each sound

\begin{tabular}{lll}
\hline sound & Spelling reference & Remarks \\
\hline$/ \mathrm{h} /$ & hat & One spelling reference \\
$/ \mathrm{m} /$ & money & \\
$\mathrm{b}$ & bat, buy & Two spelling references \\
$/ \mathrm{f} /$ & fat, phone & \\
$/ \mathrm{k} /$ & cat, kit, school, back & Three or more spelling references \\
$/ \mathrm{n} /$ & nut, gnat, know & \\
\hline
\end{tabular}

In case of intensive teaching and practicing spelling rules, the Logic of English Approach classifies 30 rules of spelling. In each rule, students try to discover the rule through various examples and they attempt to know to what extent does the rule affect by the arrangement of consonants and vowels as well as the Latin spelling rules. This point was fully discussed by Bosman and Bartelings (2003) when they claimed that spelling is an essential and complex skill involving multiple components, including visual memory, phoneme-grapheme 
awareness, as well as, orthographic and morpho-phonemic knowledge.

Similarly, Johnson (2013) revealed that the relationship between spelling and reading is so close that investigators believe that learning about spelling tends to enhance student's reading proficiency. Moreover, Adams (1990) stated that learning about spelling contributes to reading development, including children's ability to pronounce words correctly and decode unknown words.

As per the Logic of English Approach, to teach English well, instructors need to move away from teaching only the names of the 26 letters and some of their sounds to teaching the true phonics and phonograms of English intensively. Phono means 'sound' and gram means 'picture'. A phonogram, therefore, is a picture that represents a sound. Children's minds are trained to categorize phonemes in their first language, which may conflict with English phonemes. For example, Spanish-speaking children may speak, read, and write ch in place of sh because in Spanish language, these two combinations produce the same phoneme.

According to the Logic of English Approach, phonics instruction is the best way of teaching reading skills. This means students have to learn how letters correspond to sounds and how to use this awareness in reading and spelling. In this regard, CIERA (2001) reported that there is a systematic and predictable relationship between written letters and spoken sounds. In order to focus on the concept of phonics instructions, the Logic of English Approach creates a particular section named ' The Power of Roots' where one can find the meanings of English word roots, a list of all derivative words that belong to a certain root as well as the suffixes and prefixes of word roots.

\section{Data Analysis}

8.1 Foundations for Reading: Phonemic Awareness and Phonograms.

Table 2. Leading learners to the next stage should be done through Oral language development stage

\begin{tabular}{lll}
\hline Responses & Frequency & Percentage \% \\
\hline Strongly agree & 6 & 21.5 \\
Agree & 20 & 71.4 \\
Neutral & 02 & 7.1 \\
Disagree & 00 & 0.00 \\
Strongly Disagree & 00 & 0.00 \\
Total & 28 & 100 \\
\hline
\end{tabular}

Concerning phonemic awareness and phonograms as foundations for reading, we have come across the fact that twenty six subjects out of twenty eight believe that leading learners to the next stage should be done through Oral language development stage. 


\section{Macrothink \\ Education and Linguistics Research \\ ISSN 2377-1356 \\ 2016, Vol. 2, No. 1}

Table 3. Following written language development stages improves learners reading skills

\begin{tabular}{lll}
\hline Responses & Frequency & Percentage \% \\
\hline Strongly agree & 14 & 50 \\
Agree & 14 & 50 \\
Neutral & 00 & 0.00 \\
Disagree & 00 & 0.00 \\
Strongly Disagree & 00 & 0.00 \\
Total & 28 & 100 \\
\hline
\end{tabular}

In the same way, the subjects think that following written language development stages improves learners reading skills. This thought is clearly seen in Table 3 where the responses of all the twenty eight subjects agree upon the fact that following written language development stages certainly improves learners reading skills.

Table 4. Phonemic awareness is basic foundation of reading development

\begin{tabular}{lll}
\hline Responses & Frequency & Percentage \% \\
\hline Strongly agree & 18 & 64.3 \\
Agree & 08 & 28.6 \\
Neutral & 02 & 7.1 \\
Disagree & 00 & 0.00 \\
Strongly Disagree & 00 & 0.00 \\
Total & 28 & 100 \\
\hline
\end{tabular}

As it shown in the above table, the subjects were asked about phonemic awareness as a basic foundation of reading development. The responses of the subjects reveal that phonemic awareness as a basic foundation of reading development is highly considered to the extent that no disagree responses.

Table 5. Learning by phonograms helps learners develop reading skills

\begin{tabular}{lll}
\hline Responses & Frequency & Percentage \% \\
\hline Strongly agree & 18 & 64.3 \\
Agree & 10 & 35.7 \\
Neutral & 00 & 0.00 \\
Disagree & 00 & 0.00 \\
Strongly Disagree & 00 & 0.00 \\
Total & 28 & 100 \\
\hline
\end{tabular}




\section{N Macrothink}

Finally, in the area of foundations for reading: phonemic awareness and phonograms, the responses of the subjects show that learning by phonograms is one of the basic reasons that help learners develop reading skills.

To sum up, the responses of the subjects concerning phonemic awareness and phonograms as foundations for reading, we have come across the fact that this area can be developed through leading learners to the next stage using oral language development stage, (Table 2). In the same way, following written language development stages improves learners reading skills, (Table 3). Similarly, the phonemic awareness as a basic foundation of reading development is highly appreciated (Table 4). Finally, in the area of foundations for reading, learning by phonograms supports learners develop reading skills.

\subsection{Learning Styles and Differences}

Table 6. The way individual learner prefers to learn something is important for developing reading skills

\begin{tabular}{lll}
\hline Responses & Frequency & Percentage $\%$ \\
\hline Strongly agree & 18 & 64.3 \\
Agree & 10 & 35.7 \\
Neutral & 00 & 0.00 \\
Disagree & 00 & 0.00 \\
Strongly Disagree & 00 & 0.00 \\
Total & 28 & 100 \\
\hline
\end{tabular}

In the area of learning styles and differences the responses of the subjects give indication that the way individual learner prefers to learn something is so important for developing reading skills.

Table 7. Multi-sensory phonogramme instruction: All students learn faster and deeper with multi-modality teaching

\begin{tabular}{lll}
\hline Responses & Frequency & Percentage \% \\
\hline Strongly agree & 07 & 25 \\
Agree & 13 & 46.4 \\
Neutral & 08 & 28.6 \\
Disagree & 00 & 0.00 \\
Strongly Disagree & 00 & 0.00 \\
Total & 28 & 100 \\
\hline
\end{tabular}

As it is well known that one of the directions of learning styles and differences is 
multi-sensory phonogramme instruction. The responses of the subjects have revealed that all students learn faster and deeper with multi-modality teaching.

Table 8. In reading and physical development, many children's eyes struggle to consistently track left to right

\begin{tabular}{lll}
\hline Responses & Frequency & Percentage $\%$ \\
\hline Strongly agree & 10 & 35.72 \\
Agree & 14 & 50 \\
Neutral & 02 & 7.14 \\
Disagree & 02 & 7.14 \\
Strongly Disagree & 00 & 0.00 \\
Total & 28 & 100 \\
\hline
\end{tabular}

As expected in learning styles and differences that in reading and physical development, many children's eyes struggle to constantly during reading skill.

Table 9. Learners must be trained for a good physical reading development

\begin{tabular}{lll}
\hline Responses & Frequency & Percentage \% \\
\hline Strongly agree & 16 & 57.2 \\
Agree & 10 & 35.7 \\
Neutral & 02 & 7.1 \\
Disagree & 00 & 0.00 \\
Strongly Disagree & 00 & 0.00 \\
Total & 28 & 100 \\
\hline
\end{tabular}

In the final area of learning styles and differences, the result of the study confirms that 26 out of 28 responses support training of learners for a better physical reading enhancement.

\section{Summary}

To sum up, the responses of subjects revealed that the way individual learner prefers to learn something is important for developing reading skills. All students learn faster and deeper with multi modality teaching. In reading and physical development, many children's eyes make great effort to follow their track of reading. Also learners must be trained for a good physical reading development. The concluding positive results have proved the effectiveness of the Logic of English Approach on the development of reading fluency and comprehension of Saudi EFL Learners.

\section{Discussion}

Reading fluency and comprehension have been considered as ones of the major components that strong readers gained. Many researchers have demonstrated various ways and techniques 
for developing reading fluency rate. In order to enhance students' reading fluency, lots of teaching methods have been implemented. A number of studies have suggested that an extensive reading (ER) program can lead to the improvement of L2 learners' reading rate. Samuel (2006); Blevins (2005) claimed that ER is an effective approach to improve learners' reading fluency.

For developing reading fluency, a study of extensive reading in EFL, Iwahori,Y. (2008) examined the effectiveness of ER on reading rates of high school students in Japan. In this study, students were provided with graded readers and comic books as reading material they would find enjoyable. Pre tests and post tests of reading rate and language proficiency were administrated and a t test was used to compare means of rates and language proficiency within groups. Results indicate that ER is an effective approach to improve students' rate and general language proficiency.

Another program, repeated reading (RR) is equally conducted. In the RR approach, L2 learners read specified passages from graded readers repeatedly in order to increase learners' sights recognition of words and phrases, resulting in increased fluency and comprehension (Taguchi, Mass, \& Gorsuch, 2004).

Some studies have revealed that repeated reading as well as extensive reading, together, can act a vital role in the development of reading fluency. (Taguchi, et al., 2004) conducted a study on how assisted repeated reading and extensive reading affect fluency development. Some comparisons of Japanese university students' performances in repeated reading and extensive reading programs are also made in attempt to see gains in reading fluency and comprehension. The results of the study show that RR is as promising a method as ER for enhancing second and foreign language readers' fluency.

Erion and Ronka (2004) described a procedure for improving oral reading fluency that is easy for parents to learn and to carry out. Teachers may not always have the time to do sufficient practice for children in the classroom to achieve fluent oral reading so, parents are trained and asked to work with their children for 15 minutes a day. This experience has confirmed that the technique is most successful when there is follow-up and continued contact between the parents and school personnel.

Lori, Tracey, and Derwing (2013) examined several popular integrated skills textbooks used in Language Instruction for Newcomers to Canada (LINC) and English as a second language (ESL) programs for pragmatics and oral reading activities. They wanted to know to what extent textbooks focus on pragmatics and oral fluency, as well as the range of activities featured in each. They determined that oral fluency is not a major focus in integrated skills texts and these integrated textbooks were not very useful for the development of oral fluency.

In this study, the researcher assumes that the Logic of English Approach is the best program for enhancement of learners reading skills. It is completely different from the previous ones. This method, first, attempts to specify factors that create the problem. And then, it provides fundamental solutions to the problem. In 'RR' \&'ER' programs, for instance, teachers make selection of exercises, prepare them and teach them to their students. But the Logic of 
English has its own resources and materials and it gives explanation of how to make use of these materials. This Approach focuses on the following points:

The Approach uses oral language development to lead learners to the next stages of learning. It also follows the written language development stages to improve learners reading skills. It focuses chiefly on students' phonemic awareness as a basic groundwork of reading development. It always makes use of phonograms to help learners develop reading fluency. The Approach also concentrates mostly on individual learning style and differences. According to this Approach, the way individual learner prefers to learn new information is very necessary, therefore, the Approach always deals with multi-sensory phonogram instructions because students always learn better and deeper with multi-modality teaching. During reading, learners eyes struggle to move from side to side so, the Approach prepares a training program for learners to get an excellent physical reading improvement. For these reasons and others, the Logic of English Approach is the most effective method to develop English reading fluency and reading comprehension.

\section{Conclusion}

This study attempts to come up with the following findings:

Until today, some learners are frustrated daily by the number of exceptions to the rules of English language. And finally, the logic of English Approach brings a comprehensive list of English Language rules which gives evidence and justifications to these exceptions (See Appendix A).

Furthermore, there are 30 spelling rules which interplay with the phonograms to have some positive effects on the spelling and the pronunciation of words. These rules almost always apply to a majority of English words and explain why they are pronounced and spelled in a particular way. On the other hand, in English classes, there must be an intensive teaching and practice of phonics and word roots to develop students reading fluency and reading comprehension. Therefore, the Logic of English Approach is considered to be an effective method that maintains reading comprehension of Saudi EFL learners.

\section{References}

Adams, M. (1990). Beginning to read: Thinking and learning about print. Cambridge, MA: MIT Press.

Aro, M., \& Wimmer, H. (2003). Learning to Read: English in Comparison to Six More Regular Orthographies. Applied Psycholinguistics,

Baroody, A. E., \& Diamond, K. E. (2012). Links Among Home Literacy. Environment, Literacy Interest, and Emergent Literacy Skills in Preschoolers at Risk for Reading Difficulties. Special Education, 32(2), 78-87.

Baugh, A., \& Thomas, C. (2002). A history of the English Language. London: Henly and Boston.

Bayetto, A. (2013). Oxford literacy assess. South Melbourne: Oxford University Press. 
Bosman, A., \& Bartelings, M. (2003). Visual Dictation Improves the Spelling Performance of Three Groups of Dutch Students with Spelling Disabilities. Learning Disability Quarterly, 26(4).

Creswell, W. (2014). Educational Research: Planning, Conducting and Evaluating Quantitative and Qualitative Research (4th ed). UK: Pearson.

Eide, D. (2012). The Logic of English, A Systematic Approach to Reading, Spelling, and Writing (2nd ed). USA: Pedia Learning Inc.

Eide, D. (2012). Essentials The Logic of English Manuscript Workbook. USA: Pedia Learning Inc.

Eide, D. (2012). Uncovering the Logic of English, A common-Sense Approach to Reading, Spelling, and Literacy (2nd ed.) USA: Pedia Learning Inc.

Eide, D. (2012). Uncovering the Logic of English, Cursive Handwriting. USA: Pedia Learning Inc.

Eide, D. (2012). Uncovering the Logic of English, Training Manual. USA: Pedia Learning Inc.

Erion, J., \& Ronka, C. S. (2004). Improve Reading Fluency with Parent tutoring. Teaching Exceptional Children Plus, 1(2), 11.

Faver, S. (2008). Repeated Reading of Poetry Can Enhance Reading Fluency. Reading Teacher, 62(4), 350-352. http://dx.doi.org/10.1598/RT.62.4.8

Fromkin, V., Rodman, R., \& Hyams, N. (2003). An introduction to Language (7th ed) Boston: Thomson.

Geva, E., \& Zadeh, Z. Y. (2006). Reading Efficiency in Native English-Speaking and English-as-a-Second-Language Children: The Role of Oral Proficiency and Underlying Cognitive-Linguistic Processes. Scientific Studies of Reading, 10(1), 31-57. http://dx.doi.org/10.1207/s1532799xssr1001_3

Graf, S., Liu, T. C., \& Kinshuk. (2010). Analysis of learners' navigational behavior and their learning styles in an online course. Journal of Computer Assisted Learning, 26(2), 116-131. http://dx.doi.org/10.1111/j.1365-2729.2009.00336.x

Hauptman, H., \& Cohen, A. (2011). The synergetic effect of learning styles on the interaction between virtual environments and the enhancement of spatial thinking. Computers \& Education, 57(3), 11. http://dx.doi.org/10.1016/j.compedu.2011.05.008

Hiebert, et al., (2002). A Knowledge Base for the Teaching Profession: What Would It Look Like and How Can We Get One? Educational Researcher, 31(5), 3-15. http://dx.doi.org/10.3102/0013189X031005003

Hogan, T., Catts, H., \& Little, T. (2005). The relationship between phonological awareness and reading. Language, Speech, and Hearing Services in Schools, 36, 285-293. 
http://dx.doi.org/10.1044/0161-1461(2005/029)

Huang, G-J., Sung, H.-Y., Hung, C-M., \& Hung, I. (2013). A Learning Style Perspective to Investigate the Necessity of Developing Adaptive Learning Systems. Educational Technology \& Society, 16(2), 188-197.

Huang, L. V. (2008). Increasing Reading Fluency through Student-Directed Repeated Reading and Feedback. The California School Psychologist, 13(1), 33-40. http://dx.doi.org/10.1007/BF03340940

Iwahori, Y. (2008). Developing Reading Fluency: A study of Extensive Reading in EFL. Reading in A foreign Language, 20(4).

Klauda, S. L., \& Guthrie, J. T. (2008). Relationships of Three Components of Reading Fluency to Reading Comprehension. Journal of Educational Psychology, 100(2), 310-321. http://dx.doi.org/10.1037/0022-0663.100.2.310

Kristi, L., \& Edward, J. (2011). Improving Oral Reading Fluency With A peer-mediated Intervention. Journal of Applied Behavior Analysis.

Landerl, K., \& Wimmer, H. (2008). Development of word reading fluency and spelling in a consistent orthography: An 8-year follow-up. Journal of Educational Psychology, 100(1), 150-161. http://dx.doi.org/10.1037/0022-0663.100.1.150

Lori, G., Tracey, M., \& Derwing, T. (2013). To What Extent Do Popular ESL Textbooks Incorporate Oral Fluency and Pragmatic Development? TESL Canada Journal, 30.

Mc. Guinness, D. (2004). Early Reading Instruction: What Science Really Teaches Us about How to Teach Reading. Cambridge, MA: Bradford Books.

Oviedo, P., \& Gonzalez, R. (2013). Diagnostic Assessment and Treatment of Reading Difficulties: A case Study of Dyslexia.US-China Education Review, 3(5).

Rasinski, T., \& Padak, N. (2013). From Phonics to Fluency. Effective Teaching of Decoding and Reading Fluency in the Elementary School (3rd ed). USA: Pearson Education.

Rekha. (2014). Relationship Between Reading and Spelling Abilities Among Elementary School Students of Punjab. International Journal of Research in Humanities, Arts and Literature, 2(3), 33-38.

Richards, J. C., \& Schmidt, R. (2002). Longman Dictionary of Language Teaching \& Applied Linguistics (3rd ed). Harlow: Longman.

Rizopoulos, L. (2004). Traditional and Innovative Approaches to Fluency Development: The Neglected Area of the Curriculum. The Language and Literacy Spectrum, 14.

Schmitt, N. (2011). An Introduction to applied Linguistics. London: England.

Schmitt, N. (2000). Vocabulary in English Language Teaching. Cambridge: Cambridge University Press. http://dx.doi.org/10.1093/elt/54.4.400 


\section{Macrothink \\ Education and Linguistics Research \\ ISSN 2377-1356 \\ 2016, Vol. 2, No. 1}

Shiela R. Alber- Morgan. (2006) Ten ways to Enhance the Effectiveness of Repeated Readings. Journal, JEIB, 3(3).

Taguchi, E. Maass, M., \& Gorsuch, G. J. (2004). Developing Reading Fluency in EFL: How assisted repeated reading and extensive reading affect fluency development. Reading in a Foreign Language, 16(10).

Tahaineh, Y. (2012). The Awareness of the English Word- Formation Mechanisms is a Necessity to Make an Autonomous L2 Learners in EFL Context. Journal of Language Teaching and Research, 3(6), 1105-1113. http://dx.doi.org/10.4304/jltr.3.6.1105-1113

Tyler, A., \& Nagy, W. (1990). Use of derivational morphology during reading. Cognition, 36(1), 17-34. http://dx.doi.org/10.1016/0010-0277(90)90052-L

Waldron, C. H. (2008). If I Read Better, Will I Score Higher? The Relationship Between Systematic Oral Reading Fluency Instruction and Standardized Reading Achievement Test Outcomes. Pennsylvania: University of Pennsylvania.

Yildirim, K. K., \& Rasinski, T. (2014). Reading Fluency Beyond English: Investigations into Reading Fluency in Turkish Elementary Students. International Electronic Journal of Elementary Education.

Yudintseva, A. (2015). Game-Enhanced Second Language Vocabulary Acquisition Strategies: A Systematic Review. Open Journal of Social Sciences, 3, 101-109. http://dx.doi.org/10.4236/jss.2015.310015

\section{Appendix A}

\section{English Spelling Rules}

Rule 1 C always softens to /s/ when followed by E, I, or Y. Otherwise, C says $/ \mathrm{k} /$.

Rule 2 G may soften to /j/ only when followed by E, I, or Y. Otherwise, G says /g/.

Rule 3 English words do not end in I, U, V, or J.

Rule 4 A E O U usually say their names at the end of a syllable.

Rule 5 I and Y may say $/ \tilde{1} /$ or $/ \overline{1} /$ at the end of a syllable.

Rule 6 When a one-syllable word ends in a single vowel Y, it says $/ \overline{1} /$.

Rule 7 Y says /êe/ only at the end of a multisyllable base word. I says/ē/ at the end of a syllable that is followed by a vowel and at the end of foreign words.

Rule 8 I and $\mathrm{O}$ may say $/ \overline{\mathbf{1}} /$ and $/ \overline{\mathrm{o}} /$ when followed by two consonants.

Rule 9 AY usually spells the sound $/ \bar{a} /$ at the end of a base word.

Rule 10 When a word ends with the phonogram A, it says /ä/. 


\section{Macrothink

Rule 11 Q always needs a $U$; therefore, $U$ is not a vowel here.

Rule 12 Silent Final E Rules

12.1 The vowel says its name because of the E.

12.2 English words do not end in $\mathrm{V}$ or $\mathrm{U}$.

12.3 The $\mathrm{C}$ says /s/ and the G says / $\mathrm{j} /$ because of the E.

12.4 Every syllable must have a written vowel.

12.5 Add an E to keep singular words that end in the letter S from looking plural.

12.6 Add an E to make the word look bigger.

12.7 TH says its voiced sound /TH/ because of the E.

12.8 Add an E to clarify meaning.

12.9 Unseen reason.

Rule 13 Drop the silent final E when adding a vowel suffix only if it is allowed by other spelling rules.

Rule 14 Double the last consonant when adding a vowel suffix to words ending in one vowel followed by one consonant, only if the syllable before the suffix is accented.*

*This is always true for one-syllable words.

Rule15 Single vowel Y changes to I when adding any ending, unless the ending begins with I.

Rule 16 Two I's cannot be next to one another in English words.

Rule 17 TI, CI, and SI are used only at the beginning of any syllable after the first one.

Rule $18 \mathrm{SH}$ spells /sh/ at the beginning of a base word and at the end of the syllable. SH never spells /sh/ at the beginning of any syllable after the first one, except for the ending -ship.

Rule 19 To make a verb past tense, add the ending -ED unless it is an irregular verb.

Rule 20 -ED, past tense ending, forms another syllable when the base word ends in $/ \mathrm{d} / \mathrm{or} / \mathrm{t}$ / Otherwise, -ED says $/ \mathrm{d} /$ or $/ \mathrm{t} /$.

Rule 21 To make a noun plural, add the ending -S unless the word hisses or changes, then add -ES. Occasional nouns have no change or an irregular spelling. 


\section{Macrothink \\ Education and Linguistics Research \\ ISSN 2377-1356 2016, Vol. 2, No. 1}

Rule 22 To make a verb 3rd person singular, add the ending -S, unless the word hisses or changes, then add -ES. Only four verbs are irregular.

Rule 23 Al- is a prefix written with one $\mathrm{L}$ when preceding another syllable.

Rule 24 -Ful is a suffix written with one $\mathrm{L}$ when added to another syllable.

Rule 25 DGE is used only after a single vowel which says its short (first) sound.

Rule 26 CK is used only after a single vowel which says its short (first) sound.

Rule 27 TCH is used only after a single vowel which does not say its name.

Rule 28 AUGH, EIGH, IGH, OUGH. Phonograms ending in GH are used only at the end of a base word or before the letter T. The GH is either silent or pronounced /f/.

Rule 29 Z, never S, spells /z/ at the beginning of a base word.

Rule 30 We often double F, L, and S after a single vowel at the end of a base word. Occasionally other letters also are doubled.

Note: The rules are arranged as found in the Logic of English Approach

\section{Copyright Disclaimer}

Copyright reserved by the author(s).

This article is an open-access article distributed under the terms and conditions of the Creative Commons Attribution license (http://creativecommons.org/licenses/by/3.0/). 